\title{
Knowledge and skill
}

\author{
Ali Usman ${ }^{1}$, Amina Batol Gardezi ${ }^{2}$, Romana S. Durrani ${ }^{3}$, Maham Abid ${ }^{4}$ \\ Author affiliation: \\ 1. Fellow Anesthesia, Shaukat Khanum Memorial Cancer Hospital \& Research Centre, Johar Town, Lahore, Pakistan \\ 2. Resident Anesthesia, Shaukat Khanum Memorial Cancer Hospital \& Research Centre, Johar Town, Lahore, Pakistan. \\ 3. Consultant Pain Medicine \& Anesthesia, Shaukat Khanum Memorial Cancer Hospital \& Research Centre, Johar Town, \\ Lahore, Pakistan \\ 4. Consultant Radiologist, Mayo Hospital, Hospital Road, Anarkali Bazaar, Lahore, Pakistan. \\ Correspondence: Romana S, Durrani; E-mail: romanadurrani@gmail.com; Phone: +92 3344774773
}

\section{Abstract}

Human abilities are often described to be comprising of many synonymous traits including efficiency, proficiency, capability, and competency etc. The researchers include three main pillars of an individual professional or a whole system; e.g., knowledge, skill and attitude. This invited editorial covers the first two of the three, although all the three must interplay to enhance the abilities of healthcare professionals. The need of a balance of both has been emphasized, as without the one, the second will be become useless.

Key words: Knowledge; Skill; Ability; Training

Citation: Usman A, Gardezi AB, Durrani RS, Abid M. Knowledge and skill. Anaesth. pain intensive care 2021;25(5):_; DOI: $10.35975 / a p i c . v 25 i 5.1620$

Received: September 15, 2021, Accepted: September 20, 2021

Editor's Note: This invited editorial view focuses on a very important aspect of healthcare profession, e.g., the importance of acquiring adequate knowledge and the learning to apply this knowledge into practical skills. Knowledge without skill and the skill without knowledge, both are non-beneficial in the medical profession. Although this is a broad topic, but the authors were requested to emphasize the application of knowledge and skill in the fields of anesthesiology, Pain management, intensive care and resuscitation.

Two words which describe the human abilities are knowledge and skill. At first glance, these two look to be synonymous, but you think about it more deeply and you will soon realize that the two concepts are entirely different. Knowledge refers to the theoretical knowledge gained in any subject while skill refers to practical application of the knowledge. Knowledge can be learned, while the skill requires a hands-on demonstration and can be innate.

These terms are sometimes used interchangeably because both are very closely related. In fact, both augment each other and to achieve a particular goal the right proportions of both are the key.

Knowledge can be found practically anywhere in your surroundings and can be acquired from almost everything around you. With knowledge one can increase his ability to think and solve problems differently (Box 1).
To achieve excellence in any profession you require both a working knowledge and the learned skills to apply that knowledge into practice; whether it is the field of anesthesiology, pain management, intensive care or resuscitation. Whatever is not in your mind, your hands cannot perform.

Skill is defined as the ability which is obtained through repeated practice. It is the ability to do something with expertise, to perform things, to apply your knowledge effectively and easily.

There are three types of skills

1. Transferable skill: Skill you can teach and learn

2. Personal skill: Skill related to your own attributes

3. Knowledge based skill: Skill based on knowledge you have acquired over a period of time.

A very experienced laborer can build large blocks, but to transform these into The Great Pyramids of Giza one 
has to have the perfect knowledge of architecture and geometry. Knowledge is incomplete without its practical implementation and similarly skill without knowledge is merely a fluke.

Hiring in a profession, especially in the medical field, is usually governed by the number of professional degrees that an individual possesses whereas 'skill gap' is ignored altogether. A great scholar of intensive care will

\begin{tabular}{|c|c|}
\hline \multicolumn{2}{|c|}{ Box 1: Types of knowledge ${ }^{9}$} \\
\hline $\begin{array}{l}\text { Type of } \\
\text { knowledge }\end{array}$ & Inference \\
\hline $\begin{array}{l}\text { Posteriori } \\
\text { knowledge }\end{array}$ & $\begin{array}{l}\text { Refers to what comes after } \\
\text { knowledge }\end{array}$ \\
\hline Prior knowledge & $\begin{array}{l}\text { Knowledge comes before the } \\
\text { argument }\end{array}$ \\
\hline $\begin{array}{l}\text { Dispersed } \\
\text { knowledge }\end{array}$ & $\begin{array}{l}\text { Information that is divided in } \\
\text { many sources }\end{array}$ \\
\hline Domain knowledge & $\begin{array}{l}\text { Understanding about any } \\
\text { specific field }\end{array}$ \\
\hline $\begin{array}{l}\text { Empirical } \\
\text { knowledge }\end{array}$ & $\begin{array}{l}\text { Knowledge gained from } \\
\text { qualitative/quantitative } \\
\text { research }\end{array}$ \\
\hline $\begin{array}{l}\text { Encoded } \\
\text { knowledge }\end{array}$ & $\begin{array}{l}\text { Knowledge delivered in codes, } \\
\text { signals and signs }\end{array}$ \\
\hline Explicit knowledge & $\begin{array}{l}\text { Knowledge that can be easily } \\
\text { expressed verbalized }\end{array}$ \\
\hline Known unknown & $\begin{array}{l}\text { Knowledge you think you know } \\
\text { but you don't know }\end{array}$ \\
\hline Meta knowledge: & $\begin{array}{l}\text { To define knowledge, to } \\
\text { understand knowledge }\end{array}$ \\
\hline $\begin{array}{l}\text { Procedural } \\
\text { knowledge }\end{array}$ & $\begin{array}{l}\text { Knowledge which is to know } \\
\text { how to do things }\end{array}$ \\
\hline $\begin{array}{l}\text { Propositional } \\
\text { knowledge }\end{array}$ & $\begin{array}{l}\text { Knowledge that is descriptive } \\
\text { declarative or constative }\end{array}$ \\
\hline Situated knowledge & $\begin{array}{l}\text { Knowledge comes from a } \\
\text { viewpoint }\end{array}$ \\
\hline Tacit knowledge & $\begin{array}{l}\text { Knowledge to do something or } \\
\text { to master in something }\end{array}$ \\
\hline
\end{tabular}

kill his patient during cardiopulmonary resuscitation, if he doesn't know precisely at what spot he has to compress the victim's chest. Similarly if he hasn't learnt the skill to insert a chest tube in a patient of tension pneumothorax, he will be panicked and resort to call other clinicians, who might have the skill to do so in an acute emergency.

An important consideration is the timing of the development of either of the two, whether the skill should be refined first and then reinforced with the knowledge or the knowledge should be acquired prior to the skill; one may advocate any of the two models. As a general principle, theoretical knowledge must be acquired first about the pathophysiology of different clinical conditions and the real need of a set of skill to apply in any clinical scenario.

The interplay of these two specificities is even more important in anesthesia where the complexity of patientcare and advanced surgical techniques require a wide range of professional knowledge and skills. Without knowledge a skill is partially beneficial, and without skill a knowledge is absolutely useless.

Different methods have been used to assess the clinical skills in anesthesia practice, including direct observation by the supervisor, checklists and global rating scales; among these the rating scales are considered to be the most specific and objective in assessing the skills. They have good and comparable reliability. ${ }^{1-4}$

\section{Training Programs:}

The training programs, currently in place have evolved over the years and have incorporated the essential components of learning. The set of skills required in anesthesiology can broadly be divided into two categories

i) Technical skills:

ii) Non-technical skills: The non-technical skills can further be divided into two groups

a. Cognitive / mental skills, that include but not limited to situational awareness, stress management, decision making, planning and interpretation of the problem, and

b. Interpersonal / social skills including teamwork, leadership, role playing and communication.

In anesthesiology, the practical implication of both the knowledge and skills takes more importance because of the acute nature of the clinical situations faced. Here the concept of System 1 and System 2 by Daniel Kahneman is worth mentioning, the System 1 is prompt and impulsive and requires virtually no thinking and very little processing, while the System 2 is slow, deliberative and logical, and it requires processing of the information. The clinical knowledge needs to be on the System 1 and the acquired skill can be on the System 2 .

The excellence in the medical profession can be achieved with a combination of different characteristics; a wellknown triangle of knowledge, skills and attitude summarizes what was observed by Smith et al. in their survey of defining excellence in anesthesiology. They found that the combination of an individual's own qualities and the environment in which he works is very important to achieve excellence. Thus, not only trainees but also educational supervisors, heads of departments, and those responsible for organizing training systems, all have a part to play in the encouragement of excellence. 
They also observed that knowledge for its own sake (personal involvement in research) was not rated highly, but applied knowledge was judged to underlie many of the most important categories.

It has been observed that evaluation motivates learning. ${ }^{5}$ Established tools for evaluations in anesthesiology currently tend to focus broadly on defined technical skills but usually do not take the details of procedural skills (and non-technical skills) into account. Improving the evaluation of procedural skills has the potential to promote excellence in a neglected domain of learning. So far, the research that has been conducted to improve the assessment of clinical skills evaluated different methodologies which makes the comparison difficult.

\section{How to improve collaboration between learning} and clinical skill development?

It has been observed time and again that applying prelearned knowledge in attaining a skill has an improved outcome compared to what can be achieved with either of the two separately and provision of medical services, anesthesiologist's performance and the patient safety can also be improved with this. ${ }^{6}$ Different models exist that improve development and assessment of individual as well as the collective performance. Gaba's process model of anesthesiologists' decision making/problem solving behavior focuses mainly on the individuals own processing and application of the knowledge and decision making process. ${ }^{7}$ Whereas, the second model, Helmreich, discusses the multiple factors that influence the performance of the operating room teams and organizational factors. ${ }^{8}$

On an individual level every anesthesiologist possesses a bit of all the traits of a clinician, a research fellow and an academician; and a good anesthesiologist uses these acquired knowledges and skills in a perfect proportion at an appropriate time to ensure maximum efficiency is his/her work. Similarly, teamwork in any setup enhances its productivity by using the potentials of every team member to its maximum. There is no superior or inferior when it comes to comparing the knowledge and skills but the interplay of these two in a perfect percentage at a specific time in a particular situation which not only augments each other but also ensures improved service provision.

\section{Conflict of interest}

None declared by the authors

\section{Authors' contribution}

ABG: Introduction

AU: Training Programme \& system models

RD: Conclusion, material, correction \& formatting of manuscript

MA: Collaboration section \& final editing

\section{References}

1. Goff BA, Lentz GM, Lee D, Houmard B, Mandel LS. Development of an objective structured assessment of technical skills for obstetric and gynecology residents. Obstet Gynecol 2000; 96: 146 - 50

2. Goff BA, Nielsen PE, Lentz GM, et al. Surgical skills assessment: a blinded examination of obstetrics and gynecology residents. Am J Obstet Gynecol 2002; 186: 613 7

3. Grantcharov TP, Kristiansen VB, Bendix J, Bardram L, Rosenberg J, Funch-Jensen P. Randomized clinical trial of virtual reality simulation

4. Martin JA, Regehr G, Reznick R, et al. Objective structured assessment of technical skill (OSATS) for surgical residents. $\mathrm{Br}$ J Surg 1997; 84: 273 - 8

5. McKinley RK, Strand J, Ward L, Gray T, Alun-Jones T, Miller H. Checklists for assessment and certification of clinical procedural skills omit essential co

6. Fletcher GC, McGeorge P, Flin RH, Glavin RJ, Maran NJ. The role of non-technical skills in anaesthesia: a review of current literature. $\mathrm{Br} J$ Anaesth. 2002 Mar;88(3):418-29. doi: 10.1093/bja/88.3.418. PMID: 11990277.

7. Gaba D M. Anaesthesiology as a model for patient safety in health care BMJ 2000; 320 :785 doi:10.1136/bmj.320.7237.785

8. Helmreich RL, Schaefer H-G. Team performance in the operating room. In: Bognor M, ed. Human Error in Medicine. Mahwah, NJ: Lawrence Erlbaum Associates, 1994; 225 \pm 53

9. https://www.marketing91.com/13-types-of-knowledge/ 